\title{
Economic Analysis of Minimizing Environmental Cost Caused by Outdoor Advertising
}

\author{
Odysseas Kopsidas ${ }^{1}$, Andreas Hadjixenophontos ${ }^{1}$ and Athanasios Anastasiou ${ }^{2}$ \\ 1. School of Economics \& Business, Pafos 8042, Cyprus \\ 2 Department of Economics, University of Peloponnese, Tripolis 22100, Greece
}

\begin{abstract}
The optimal consent ration $\mathrm{C}_{\mathrm{opt}}$ of pollutant advertising in the environment can be determined as an equilibrium point in the trade off between the environmental cost, due to impact on man/land/economy and the economic cost for environmental protection. These two conflict variables are internalized within the same techno-economic objective function of total cost, which is minimized. Last, sensitivity analysis of $\mathrm{C}_{\mathrm{opt}}$ as regards the impact of the increase of environmental information/sensitization and the decrease of interest rate reveals a shifting of $\mathrm{C}_{\mathrm{opt}}$ to lower and higher values, respectively, certain positive and negative implications (i.e. shifting of $\mathrm{C}_{\mathrm{opt}}$ to lower and higher values, respectively) caused by socioeconomic are also discussed.
\end{abstract}

Key words: Environmental cost, optimization, advertising, land.

\section{Introduction}

The economic analysis of the environmental cost of outdoor advertising in real estate involves matching the environmental to the socio-economic benefit $[1,2]$. By analogy, economic analysis of the principle/consensus 'think locally, act globally' and the (now known on a theoretical and practical basis) inverse 'think globally, act locally'. Although these principles usually have a reference to environmental pollution, they can be used in solid waste and aesthetic pollution caused by outdoor advertising [3, $4]$.

\section{Methodology}

The analysis of the subject may include qualitative and quantitative characteristics. The effort to minimize the environmental costs invoked by outdoor advertising is graphically represented by the CPM (Contingent Valuation Method) [5]. Table 1 shows the number of activities required and the completion time in days $[6,7]$. The background analysis is based on a

Corresponding author: Odysseas Kopsidas, Ph.D., research field: public and environmental economics. dynamic approach $[8,9]$. The activities include the description of the techno economic/environmental system under consideration, the identification of the scientific disciplines forming the constituent sub-systems and the discrimination of the most relevant topics within these sub-systems, i.e. the individual lands where take place the advertising activity.

Environmental standards, as independent/explanatory variables of capital cost determination functions may refer to spatial points in order to protect subsystems that have a particular sensitivity or/and importance [10]. In such cases, a quantitative link is applied linking the environmental characteristics of the source of the pollution source to those of the reference points/control [11].

\section{Results and Discussion}

The minimization of environmental costs can be used as a criterion for determining the optimal value of concentration $\mathrm{C}$ of a pollutant in the environment, that is to say, a property hosting outdoor advertising. In the most common case, where socio-economic costs and private economic costs are conflicting 
Table 1 CPM chart for building an outdoor advertising infrastructure project with minimizing environmental costs.

\begin{tabular}{ll}
\hline Activity number & $\begin{array}{l}\text { Time of } \\
\text { completion } \\
\text { (in days) }\end{array}$ \\
\hline 1. Project notice & 2 \\
2. Awarding a project to a carrier & 6 \\
3. Geography of the region & 3 \\
4. Identifying advertising needs & 3 \\
5. Recording of existing infrastructures & 3 \\
6. Specifying alternatives & 1 \\
7. Technical design of outdoor advertising & 6 \\
8. Technical study on the use of special materials & 6 \\
9. An economic study of building infrastructure & 3 \\
for outdoor advertising & 3 \\
10. Economic study of the use of special materials & 2 \\
11. Environmental Impact Study for Building & 2 \\
Infrastructure for Outdoor Advertising & 2 \\
12. Environmental impact assessment of use of & 2 \\
special materials & 1 \\
13. Choice of best alternative from Scholar & 1 \\
14. Construction of infrastructure for outdoor & 8 \\
advertising & 6 \\
15. Applications of special materials & 4 \\
16. Trial operation & 1 \\
17. Repair imperfections in the infrastructure & 3 \\
18. Recheck on the use of materials & 2 \\
19. Advertising quality control & 1 \\
20. Delivery - operation & 6 \\
\hline
\end{tabular}

Table 2 Prerequisites for the CPM method.

\begin{tabular}{ll}
\hline Activity & Prerequisites \\
\hline 2 & 1 \\
$3,4,5$ & 2 \\
6 & $3,4,5$ \\
7 & 6 \\
8 & 6 \\
9 & 7 \\
10 & 8 \\
11 & 9 \\
12 & 10 \\
13 & $7,8,9,10,11,12$ \\
14 & 13 \\
15 & 13 \\
16 & 14,15 \\
17 & 16 \\
18 & 16 \\
19 & 17,18 \\
20 & 19 \\
\hline
\end{tabular}

variables, the environmental cost, which is the sum of these variables, presents a single internal minimum if social cost and private cost are functions of $\mathrm{C}$, are also continuous and monotonous. If the marginal socio-economic cost curves and marginal private economic cost curves are used, the optimal $\mathrm{C}_{\text {opt }}$ value is easily determined from the point of intersection of the marginal cost curves. Reducing the size of advertising may cause a shift in the cost of private finance with modern economies of scale, a reduction in the cost of privatization with the adoption of anti-pollution technology, a change in the socio-economic cost curve according to the perceptions of an environmentalist whose basic view is the environment after all else, and a change in the socio-economic cost curve, according to the perceptions of a 'developmentist', whose basic view is first of all, after everything else.

\section{Conclusion}

In conclusion, the functionality of the methodological framework, it is developed under the form of a logical flow chart for optimizing parameter values and independent variables has been proved by using the tradeoffs between societal/environmental and private/techno economic cost and system reliability and design/construction cost. It is worthwhile noting that both tradeoffs, the first based on cost minimization and the second based on benefit maximization, represent interdisciplinary objective functions, since their paramaters belong to the domains of Technology, Economics and Environmental Science (which is, in its turn, a multidisciplinary field).

\section{Reference}

[1] Ajzen, I., Brown, T. C., and Rosenthal, L. H. 1996. "Information Bias in Contingent Valuation: Effects of Personal Relevance, Quality of Information and Motivational Orientation." Journal of Environmental Economics and Management 30 (1): 43-57.

[2] Bedate, A., Herrero, L. C., and Sanz, J. A. 2004. "Economic Valuation of the Cultural Heritage: 
Application to Four Case Studies in Spain." Journal of Cultural Heritage 5 (1): 101-11.

[3] Kahneman, D., and Knetsch, L. J. 1992. "Valuing Public Goods: The Purchase of Moral Satisfaction.” Journal of Environmental Economics and Management 22 (1): 57-70.

[4] Bateman, I., Munro, A., Rhodes, B., Starmer, C., and Sugden, R. 1997. "A Test of the Theory of Reference-Dependent Preferences." The Quarterly Journal of Economics 112 (2): 479-505.

[5] Brown, T. C. 2005. "Loss Aversion without the Endowment Effect, and Other Explanations for the WTA-WTP Disparity." Journal of Economic Behavior and Organization 57 (3): 367-79.

[6] Hanemann, W. M. 1991. "Willingness to Pay and Willingness to Accept: How Much Can They Differ?" The American Economic Review 81 (3): 635-47.

[7] Horowitz, J. K., and McConnell, K. E. 2003.
"Willingness to Accept, Willingness to Pay and the Income Effect." Journal of Economic Behavior and Organization 51 (4): 537-45.

[8] Kling, R. W., Revier, C. F., and Sable, K. 2004. "Estimating the Public Good Value of Preserving a Local Historic Landmark: The Role of Non-substitutability and Citizen Information.” Urban Studies 41 (10): 2025-41.

[9] Kopsidas, O., and Batzias, F. 2011. "Improvement of Urban Environment and Preservation of Cultural Heritage through Experimental Economics by a Modified Contingent Valuation Method (CVM)." Recent Researches in Energy, Environment, Devices, Systems, Communications and Computers 157-62.

[10] Liao, T. F. 1994. Interpreting Probability Models: Logit, Probit, and Other Generalized Linear Models. London: Sage Publications Inc., 101.

[11] Menard, S. 2001. Applied Logistic Regression Analysis (2nd ed.). London: Sage Publications Inc.. 